\title{
Ginkgolide B promotes cell growth in endothelial progenitor cells through miR-126 and the Akt signaling pathway
}

\author{
JING CHANG ${ }^{1}$, XIN XUE ${ }^{2}$, CHUNLI SONG ${ }^{2}$, BIN LIU $^{2}$ and LIHUA GAO ${ }^{2}$ \\ Departments of ${ }^{1}$ Clinical Laboratory and ${ }^{2}$ Cardiovascular, The Second Hospital \\ of Jilin University, Changchun, Jilin 130041, P.R. China
}

Received January 2, 2016; Accepted May 3, 2017

DOI: $10.3892 / \mathrm{mmr} .2017 .7254$

\begin{abstract}
Ginkgolide B is one of the components extracted from Folium Ginkgo. It is a natural antagonist of platelet-activating factor receptor and has multiple pharmacological applications. In the present study, the effect of ginkgolide B on the proliferation of endothelial progenitor cells (EPCs) was examined, as well as its potential underlying mechanism. EPCs were cultured in various concentrations of ginkgolide $\mathrm{B}(0,1.25,5,20,80$ or $160 \mu \mathrm{g} / \mathrm{ml})$ for 24 or $48 \mathrm{~h}$ and then numbers of viable cells, apoptosis rate and caspace- 3 activity were measured. The results demonstrated that ginkgolide $\mathrm{B}$ treatment effectively promoted EPC growth, and suppressed cell apoptosis and caspase-3 activity compared with control cells. In addition, ginkgolide B treatment significantly induced the expression of miR-126, vascular endothelial growth factor and endothelial nitric oxide synthase, while it increased phosphorylation of AKT serine/threonine kinase 1 (Akt) and of p38 mitogen-activated protein kinase in EPCs. The present study therefore demonstrated that ginkgolide B promoted cell growth in EPCs through overexpression of miR-126 and activation of the Akt signaling pathway.
\end{abstract}

\section{Introduction}

Endothelial cells serve an important role in stabilizing the endangium of blood vessels. There is a plethora of research devoted to establishing methods for blood vessel endothelium repair, potentially through in vitro culture amplification of endothelial progenitor cells (EPCs) (1). Asahara et al (2) were the first to report that cells with the potential of constructing new vessels exist in the hematopoietic system and termed these cells EPCs. The discovery of EPCs therefore provides the possibility to achieve the goal of novel methods of blood

Correspondence to: Dr Xin Xue, Department of Cardiovascular, The Second Hospital of Jilin University, 218 Zi Qiang Road, Changchun, Jilin 130041, P.R. China

E-mail: xuex@jlu.edu.cn

Key words: Ginkgolide B, endothelial progenitor cells, miR-126, AKT serine/threonine kinase 1 vessel repair. EPCs are precursor cells which can be differentiated into vascular endothelial cells. EPCs in the bone marrow can be mobilized to enter the systemic circulation by various stimulating factors, including ischemia, blood vessel damage and several drugs (2). Multiple chemotactic factors (CFs) function as attractants for EPCs to direct them to the sites of damage or ischemia, and to differentiate them into mature endothelial cells, so as to promote the endothelial repair in ischemia-damaged tissues and organs (3). Thus, EPCs may have wide applications in the treatment of cardiovascular disease and revascularization. However, the clinical application of EPCs in the process of angiogenesis remains disputed.

microRNAs (miRNAs) are short oligonucleotides that regulate gene expression by acting on target genes to either translate or degrade their mRNA (4). An increasing number of studies have demonstrated that miRNAs may be important in the signal transduction and regulation of angiogenesis. miRNAs regulate the cell growth, migration and apoptosis of endothelial cells, as well as the formation of blood capillaries (4). miR-126 is one of the most important miRNAs for endothelial cell function, and it is located in the intron of epidermal growth factor-like domain 7, which is a highly-expressed gene in endothelial cells (5). In addition, miRNA-126 regulates various biological characteristics of endothelial cells, including cell differentiation, migration, cytoskeleton reconstruction, maintenance of capillary network stabilization and cell viability (6). miRNA-126 is expressed specifically in endothelial cells and promotes angiogenesis (6). Previous studies have demonstrated that the zinc finger transcription factor Kruppel-like factor 2a induces endothelial cells to express miR-126, resulting in activation of VEGF signaling and promoting angiogenesis (6).

At present, eight compounds of terpene lactones, including bilobalide A, B, C, J, M, K, L and ginkgolide B, have been extracted from the Folium Ginkgo, which consists of the dried whole leaf of the plant Ginkgo biloba (7). Bilobalide is equipped with distinctive 'lantern' molecular structure with 20 carbons, including 3 lactonic rings and 1 nonyl ring (8). It belongs to the diterpenes class of chemical compounds and is a rare natural compound (8). To date, it has not been discovered in other plants except for the Ginkgo biloba. Ginkgolide B (chemical structure illustrated in Fig. 1) has exhibited promise as a novel therapeutic for multiple conditions, 
including burn, allergic asthma, apoplexy, transplant rejection and hemodialysis (9). Ginkgolide B has been demonstrated to block nuclear factor (NF)- $\kappa \mathrm{B}$ signaling in vascular endothelial cells, to induce expression of intercellular adhesion molecule 1 , and to reduce inflammation damage induced by oxidized low density lipoprotein (10). Ginkgolide B can selectively inhibit the increase of calcium in vascular smooth muscle cells, as well as non-selectively alleviate the function of vasopressin (11). In the present study, the effect of ginkgolide B on the cell growth of endothelial progenitor cells was examined, as well as its potential mechanism through the AKT serine/threonine kinase 1 (Akt) signaling pathway and miR-126.

\section{Materials and methods}

Endothelial progenitor cell isolation and culture. The present study was approved by the Ethics Committee of The Second Hospital of Jilin University (Changchun, China). Male Sprague-Dawley rats (weight, 200-250 g, 6-8 weeks) were housed at $22-23^{\circ} \mathrm{C}$ and $55-60 \%$ humidness. Rats were sacrificed under anesthesia and mononuclear cells from bone marrow were isolated with Ficoll-Isopaque Plus (Sigma-Aldrich; Merck KGaA, Darmstadt, Germany) density-gradient centrifugation at $500 \mathrm{x}$ g at $4^{\circ} \mathrm{C}$ for $10 \mathrm{~min}$. Cells were resuspended in endothelial cell growth medium (Invitrogen; Thermo Fisher Scientific, Inc., Waltham, MA, USA) and 20\% FBS (Invitrogen; Thermo Fisher Scientific, Inc.), and were then cultured on a fibronectin-coated dish at $37^{\circ} \mathrm{C}$ in a $5 \% \mathrm{CO}_{2}$. After 4-5 days, anchorage-dependent cells were incubated with complete medium. The solution was collected and centrifuged at 1,000 x $\mathrm{g}$ for $5 \mathrm{~min}$ following washing with PBS. EPCs were collected and cultured in M199 medium (Sigma-Aldrich) containing 20\% fetal bovine serum (Invitrogen; Thermo Fisher Scientific, Inc.), 2 mM glutamine, and $1 \%$ penicillin/streptomycin in an incubator at $37^{\circ} \mathrm{C}$ with $5 \% \mathrm{CO}_{2}$. Ginkgolide B was obtained from Sigma-Aldrich; Merck KGaA and dissolved in dimethyl sulfoxide (DMSO) at a concentration of $160 \mathrm{mg} / \mathrm{ml}$. Control cells were treated with an equal volume of DMSO.

Cell Counting Kit-8 (CCK-8) assay. EPCs were cultured in 96-well plates containing different concentrations of ginkgolide B $(0,1.25,5,20,80$ or $160 \mu \mathrm{g} / \mathrm{ml})$ for 24 or $48 \mathrm{~h}$. Then, $10 \mu \mathrm{l}$ of CCK-8 solution (Invitrogen; Thermo Fisher Scientific, Inc.) was added into every well, incubated for $4 \mathrm{~h}$, and absorbance was measured at $450 \mathrm{~nm}$ using a microplate reader system (XL-818; BioTek Instruments, Inc., Winooski, VT, USA).

Apoptosis assay. EPCs were cultured in 6-well plates containing different concentrations of ginkgolide $B$ $(0,20,80$ or $160 \mu \mathrm{g} / \mathrm{ml})$ for $48 \mathrm{~h}$. Cells were washed with PBS and double-stained with fluorescein isothiocyanate (FITC)-conjugated Annexin V (Thermo Fisher Scientific, Inc.) and propidium iodide (PI; Thermo Fisher Scientific, Inc.). Apoptosis was determined by flow cytometry (FACSCalibur c6, BD Biosciences, Franklin Lakes, NJ, USA) and analyzed using Quantity One software version 3.0 (Bio-Rad Laboratories, Inc., Hercules, CA, USA).
Determination of caspase-3 activity. EPCs were cultured in 96-well plates containing different concentrations of ginkgolide B $(0,20,80$ or $160 \mu \mathrm{g} / \mathrm{ml})$ for $48 \mathrm{~h}$. Cells were then collected and lysed in ice-cold radioimmunoprecipitation assay buffer (RIPA; Cell Signaling Technology, Inc., Danvers, MA, USA) for $10 \mathrm{~min}$. Lysates were centrifuged at $12,000 \mathrm{x} \mathrm{g}$ for $10 \mathrm{~min}$ at $4^{\circ} \mathrm{C}$, and the supernatant was collected and incubated with substrate solution B $(200 \mu \mathrm{l})$ and lysate solutions $(25 \mu \mathrm{l})$ at $37^{\circ} \mathrm{C}$ for $1 \mathrm{~h}$ in the dark. Caspase-3 activity was measured at $405 \mathrm{~nm}$ using a microplate reader system (XL-818; BioTek Instruments, Inc.).

Reverse transcription-quantitative polymerase chain reaction $(R T-q P C R)$. Total RNA was extracted from EPCs following treatment with ginkgolide $\mathrm{B}$ for $48 \mathrm{~h}$, using TRIzol reagent (Invitrogen; Thermo Fisher Scientific, Inc.), according to the manufacturer's instructions. Total RNA $(1 \mu \mathrm{g})$ was reverse-transcribed into cDNA using the TaqMan MicroRNA Reverse Transcription Kit (Thermo Fisher Scientific, Inc.). qPCR was performed using SYBR Green PCR master mix (Applied Biosystems; Thermo Fisher Scientific, Inc.) on an ABI 7500HT system (Thermo Fisher Scientific, Inc.). The specific primers were as follows: miR-126, forward 5'-GGG CATTATTACTTTTGG-3' and reverse 5'-TGCGTGTCG TGGAGTC-3'; U6, forward 5'-CTCGCTTCGGCAGCA CA-3' and reverse 5'-AACGCTTCACGAATTTGCGT-3'. PCR conditions were $5 \mathrm{~min}$ at $94^{\circ} \mathrm{C}$, followed by 40 cycles of $30 \mathrm{sec}$ at $94^{\circ} \mathrm{C}, 30 \mathrm{sec}$ at $60^{\circ} \mathrm{C}$, and $45 \mathrm{sec}$ at $72^{\circ} \mathrm{C}$. The gene expression was analyzed using the $2^{-\triangle \Delta \mathrm{Cq}}$ method (12).

Western blotting. EPCs were cultured in 6-well plates containing different concentrations of ginkgolide B $(0,20$, 80 or $160 \mu \mathrm{g} / \mathrm{ml}$ ) for $48 \mathrm{~h}$. EPCs were washed twice with cold PBS and lysed with ice-cold RIPA buffer (Cell Signaling Technology, Inc., Danvers, MA, USA). Protein concentrations in supernatants were measured using the bicinchoninic acid protein assay kit (Thermo Fisher Scientific, Inc.). Extracted protein $(10 \mu \mathrm{g})$ was separated by $8-12 \%$ SDS-PAGE and transferred onto polyvinylidene difluoride membranes (Whatman; Merck KGaA). The membrane was blocked with $5 \%$ skimmed milk powder for $1 \mathrm{~h}$ at $37^{\circ} \mathrm{C}$ and then incubated with primary antibodies targeting phosphorylated (p)-Akt (sc-101629; 1:500; Santa Cruz Biotechnology, Inc., Dallas, TX, USA), endothelial nitric oxide synthase (eNOS; sc-654; 1:500; Santa Cruz Biotechnology, Inc.), p-p38 [official name mitogen-activated protein kinase (MAPK; 4511; 1:2,000, Cell Signaling Technology, Inc.)], vascular endothelial growth factor (VEGF; sc-13083; 1:500; Santa Cruz Biotechnology, Inc.) and $\beta$-actin (sc-7210; 1:500; Santa Cruz Biotechnology, Inc.), as a loading control at $4{ }^{\circ} \mathrm{C}$ overnight. Following incubation with anti-rabbit HRP-linked Antibody (7074; 1:2,000; Cell Signaling Technology, Inc.) at $37^{\circ} \mathrm{C}$ for $1 \mathrm{~h}$, protein signals were visualized with the enhanced chemiluminescence western blotting detection kit (GE healthcare, Chicago, IL, USA). Densitometry analysis was performed using Quantity One software version 3.0 (Bio-Rad Laboratories, Inc.).

Statistical analysis. Data were expressed as means \pm standard deviation $(n=3)$ using SPSS version 17 (SPSS, Inc., Chicago, 
IL, USA). One-way analysis of variance were used to compare the values of the test and control samples. $\mathrm{P}<0.05$ was considered to indicate a statistically significant difference.

\section{Results}

Ginkgolide B promotes cell growth in EPCs. The effect of ginkgolide B treatment on cell proliferation of EPCs was first examined. After 24 or 48 h of ginkgolide B treatment, the total numbers of viable endothelial progenitor cells were significantly increased compared to control cells, in a dose-dependent manner (Fig. 2). In specific, at $24 \mathrm{~h}$, treatment with $20 \mu \mathrm{M}$ ginkgolide $\mathrm{B}$ significantly increased the number of EPCs (Fig. 2A). At 48 h, treatment with either 15 or $20 \mu \mathrm{M}$ ginkgolide B significantly increased the number of EPCs (Fig. 2B).

Ginkgolide B inhibits apoptosis in EPCs. The effect of ginkgolide B on apoptosis of EPCs was examined using FITC-Annexin V/PI double-staining and flow cytometry. Compared with control, treatment with 15 or $20 \mu \mathrm{M}$ Ginkgolide B significantly inhibited the \% of apoptotic EPCs per total in 24 and 48 h (Fig. 3). Therefore, these results indicated that ginkgolide B promoted cell growth and inhibited apoptosis in EPCs.

Ginkgolide B inhibits caspase-3 activity in EPCs. Next, to explore the mechanism of ginkgolide B effect on apoptosis, the caspase-3 activity in EPCs treated with ginkgolide B was examined. As illustrated in Fig. 4, caspase-3 activity in EPCs was significantly inhibited by 15 or $20 \mu \mathrm{M}$ ginkgolide $\mathrm{B}$ treatment for $48 \mathrm{~h}$, compared with control cells. This result was consistent with the inhibition of apoptosis illustrated in Fig. 3.

Ginkgolide B induces miR-126 expression in EPCs. To further explore the mechanism of ginkgolide B effect on EPCs, miR-126 expression levels were analyzed by RT-qPCR. As illustrated in Fig. 5, treatment with 15 or $20 \mu \mathrm{M}$ ginkgolide $\mathrm{B}$ significantly increased the expression levels of miR-126 in EPCs, compared with control cells.

Ginkgolide B induces p-Akt protein expression in EPCs. Next, the effect of ginkgolide B on the Akt signaling pathway was examined. As illustrated in Fig. 6, treatment with 15 or $20 \mu \mathrm{M}$ ginkgolide B significantly increased the protein expression levels of p-Akt in EPCs, compared with control cells. These results suggested that ginkgolide B may promote cell growth via the Akt signaling pathway.

Ginkgolide B induces eNOS protein expression in EPCs. To determine the effects of ginkgolide B on eNOS protein expression in EPCs, eNOS protein expression levels were detected by western blotting. Compared with control cells, treatment with 15 or $20 \mu \mathrm{M}$ ginkgolide B significantly induced eNOS protein expression in EPCs (Fig. 6).

Ginkgolide B induces p-p38 protein expression in EPCs. The protein expression levels of p-p38 were also examined by western blotting following ginkgolide B treatment. Treatment

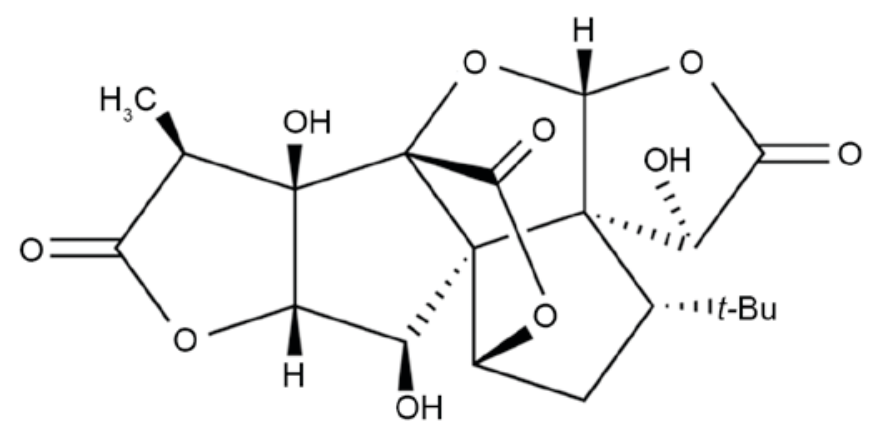

Figure 1. The chemical structure of ginkgolide B.

with 15 or $20 \mu \mathrm{M}$ ginkgolide B significantly enhanced the expression levels of p-p38 compared with control cells (Fig. 7).

Ginkgolide B induces VEGF protein expression in EPCs. Finally, to explore the potential effect of ginkgolide $B$ on angiogenesis, the protein levels of VEGF were examined in EPCs. Compared with control cells, treatment with 15 or $20 \mu \mathrm{M}$ ginkgolide $\mathrm{B}$ resulted in significantly increased VEGF protein expression levels in EPCs (Fig. 7).

\section{Discussion}

Angiogenesis is a highly-regulated process that is important in tissue repair, regeneration and embryonic development, with EPCs serving a central role in these functions (13). Previous studies have demonstrated that EPCs exhibit characteristics of directional differentiation into endothelial cells by homing in an ischemic region (14). EPCs not only participate in angiogenesis during embryonic development, but can also be differentiated into endothelial cells following birth (15). In addition, they serve a role in repairing the damaged intima, promoting angiogenesis and improving critical limb ischemia. Thus, EPCs may have a wide clinical application prospect in the treatment of coronary disease and vascular tissue (16). However, few EPCs exist in vivo, and they account for $\sim 0.05 \%$ and $0.10 \%$ of the peripheral blood mononuclear cells and marrow, respectively (17). Therefore, successful isolation of stable numbers of EPCs from marrow and peripheral blood required further experimental study and may be the key for their clinical application (17). In the present preliminary study, ginkgolide B was demonstrated to increase EPC growth, and inhibit apoptosis and caspase-3 activity in EPCs. Tang et al (18) have demonstrated that ginkgolide B promotes proliferation in bone marrow-derived endothelial progenitor cells, through the Akt/eNOS and the MAPK/p38 signaling pathways.

While angiogenesis and maintenance of accurate regulation are necessary for normal development and healing reaction following tissue damage (4). The study on the functions of miRNAs on angiogenesis originated in $2005(4,5)$. A previous study demonstrated that the expression levels of VEGF and its receptor are markedly increased in the embryonic development process of Dicer ${ }^{\text {ex } 1 / 2}$ mutant mice, resulting in vascular dysfunction in the embryonic development process. miRNAs are closely related to gene expression in endothelial cells and angiogenesis (19). To date, multiple 

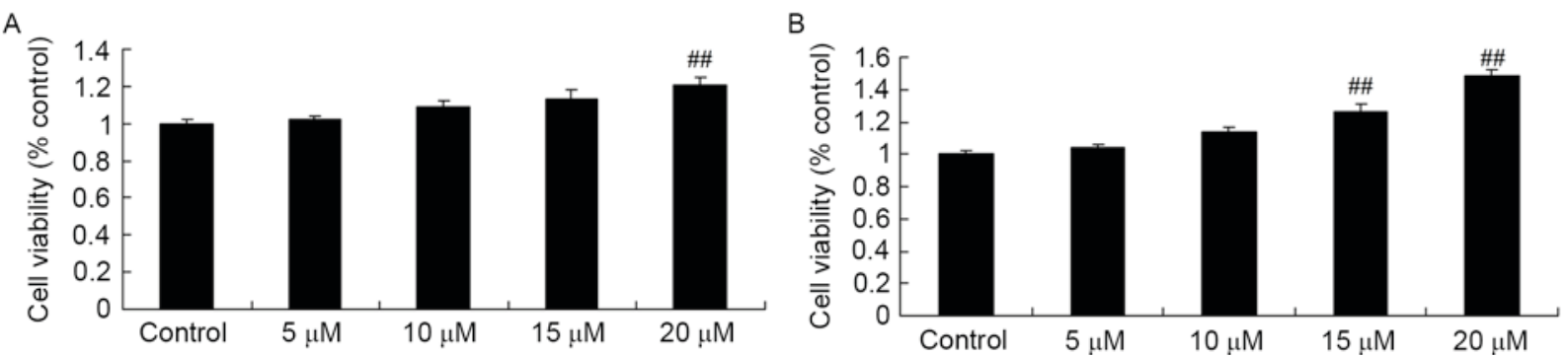

Figure 2. Ginkgolide B promotes cell growth in endothelial progenitor cells. Cells were treated with 0 (control), 5, 10, 15 or $20 \mu \mathrm{M}$ ginkgolide B for (A) 24 and (B) $48 \mathrm{~h}$, and then cell viability was measured. ${ }^{\# \#} \mathrm{P}<0.01$ compared with control.
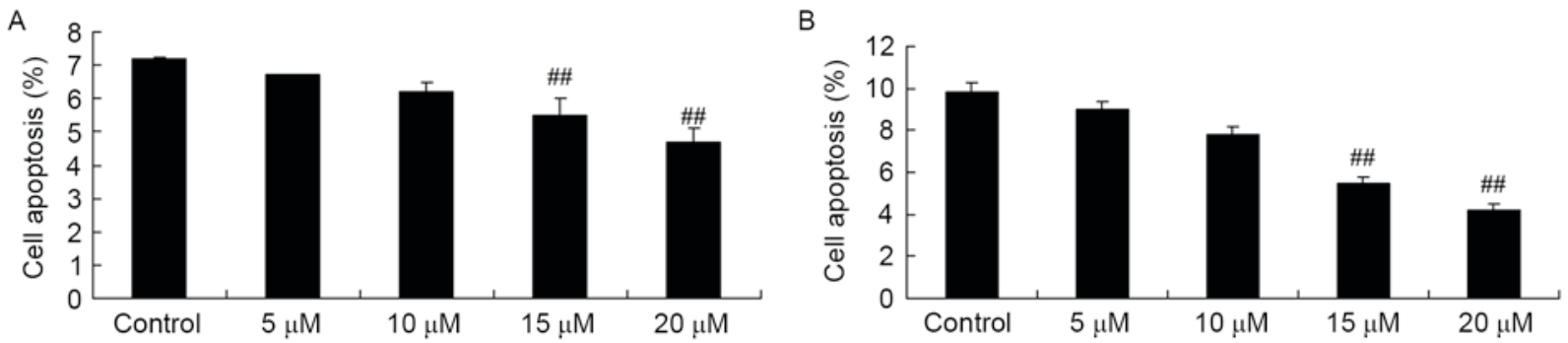

Figure 3. Ginkgolide B inhibits apoptosis in endothelial progenitor cells. Cells were treated with 0 (control), 5, 10, 15 or $20 \mu \mathrm{M}$ ginkgolide B for (A) 24 and (B) $48 \mathrm{~h}$, and then apoptosis was measured by flow cytometry. ${ }^{\# \#} \mathrm{P}<0.01$ compared with control.

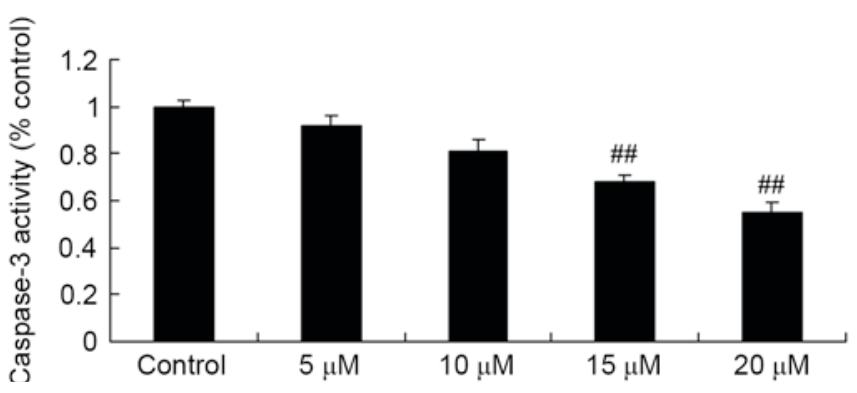

Figure 4. Ginkgolide B inhibits caspase-3 activity in endothelial progenitor cells. Cells were treated with 0 (control), 5, 10, 15 or $20 \mu \mathrm{M}$ ginkgolide B for $48 \mathrm{~h}$, and then caspase- 3 activity apoptosis was measured. ${ }^{\# \prime \prime} \mathrm{P}<0.01$ compared with control.

angiogenesis-related miRNAs have been identified, and miR-126 is the most studied among them. miR-126 is specifically expressed in endothelial cells and promotes angiogenesis (20). Vascular endothelial cells are the foundation components in angiogenesis (21), and vascular smooth muscle cells and matrix participate to form the complete blood vascular system. miR-126 not only has high expression in vascular tissues, but its expression is specific to the vascular endothelial cells (6). The present study demonstrated that ginkgolide B treatment induced miR-126 expression in EPCs. These results suggested that the effect of ginkgolide B on EPCs may be mediated by miR-126.

Few studies are available regarding the function of miR-126 in EPCs. miR-126 is highly expressed in EPCs (22). In addition, its expression is reduced by $\sim 4-5$-fold in EPC of patients with coronary disease compared with healthy subjects, suggesting that miR-126 may be important in regulating the function of EPCs (23). miR-126 impacts signal

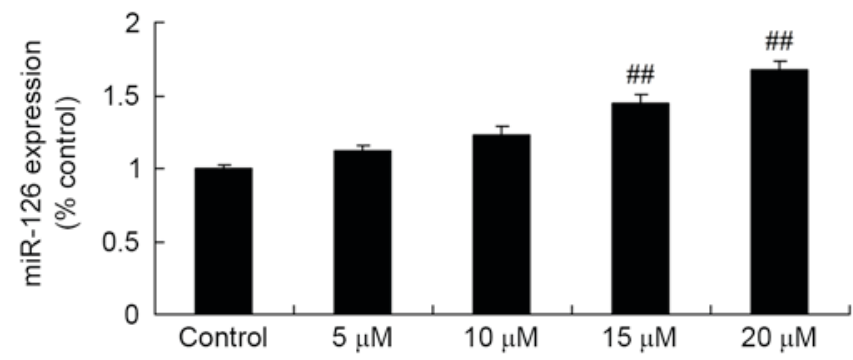

Figure 5. Ginkgolide B induces miR-126 expression in endothelial progenitor cells. Cells were treated with 0 (control), 5, 10, 15 or $20 \mu \mathrm{M}$ ginkgolide $\mathrm{B}$ for $48 \mathrm{~h}$, and then miR-126 expression levels were measured by reverse transcription-quantitative polymerase chain reaction. ${ }^{\# \#} \mathrm{P}<0.01$ compared with control.

transduction by targeting phosphoinositide 3-kinase (PI3 K) regulatory subunit 2 , resulting in inhibition of differentiation of EPCs to mesenchymal cells (24). MiR-126 has been reported as an early diagnosis marker of intimal hyperplasia of cardiovascular disease (25). It has been demonstrated that miR-126 expression in EPCs isolated from patients with diabetes is markedly reduced (24). Reduction of miR-126 expression inhibits the ability of amplification and migration of EPCs. The molecular mechanism by which miR-126 functions in EPCs to impact the Ras/ERK/VEGF and PI3K/Akt/eNOS pathways is via targeting Sprouty-related EVH1 domain-containing protein 1 (24). In the present study, the effect of ginkgolide $\mathrm{B}$ on the activation of the Akt/eNOS/p38/VEGF signaling pathways was confirmed in EPCs. Liu et al (7) reported that ginkgolide B inhibits monocyte transmigration through the PI3 K/Akt pathway in oxidized low-density lipoprotein-stimulated human umbilical vein endothelial cells. Natarelli and Schober (20) reported that 

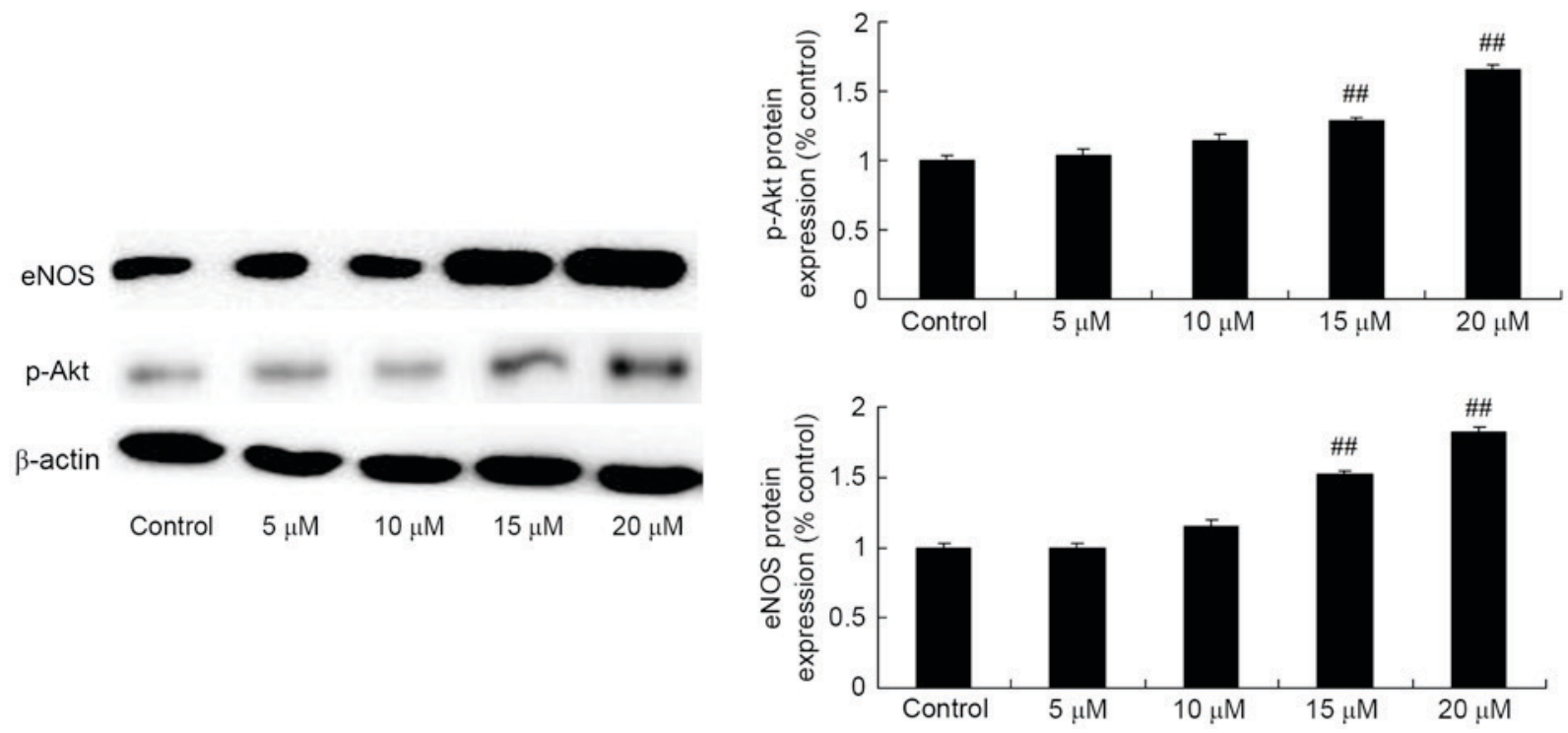

Figure 6. Ginkgolide B induces p-Akt and eNOS protein expression in endothelial progenitor cells. Cells were treated with 0 (control), $5,10,15$ or $20 \mu \mathrm{M}$ ginkgolide B for $48 \mathrm{~h}$, and then protein expression levels were measured by western blotting. Representative images and quantification are shown, with $\beta$-actin used as a normalization control. ${ }^{\# \#} \mathrm{P}<0.01$ compared with control. p-Akt, phosphorylated AKT serine/threonine kinase 1; eNOS, endothelial nitric oxide synthase.
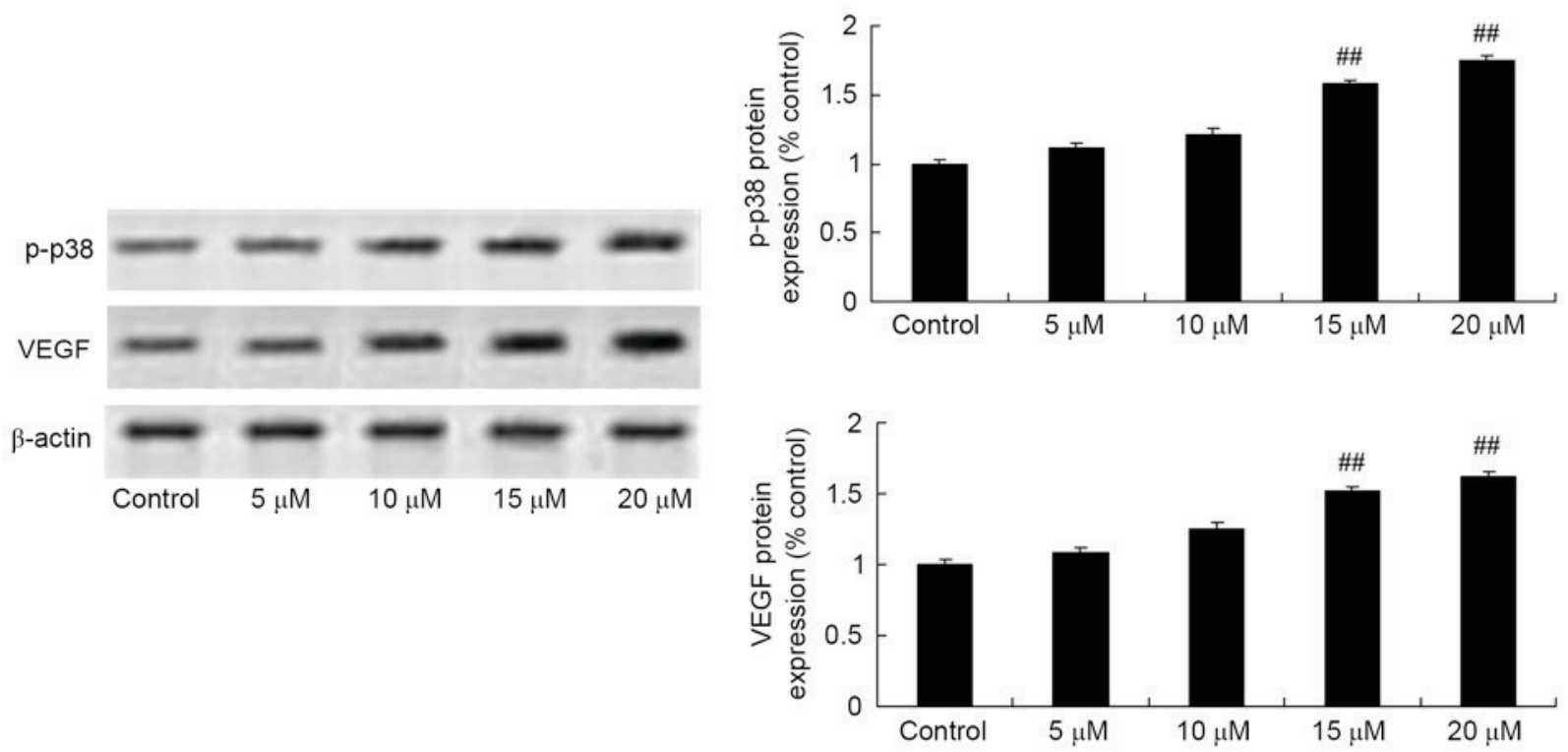

Figure 7. Ginkgolide B induces p-p38 and VEGF protein expression in endothelial progenitor cells. Cells were treated with 0 (control), 5, 10,15 or $20 \mu \mathrm{M}$ ginkgolide B for $48 \mathrm{~h}$, and then protein expression levels were measured by western blotting. Representative images and quantification are shown, with $\beta$-actin used as a normalization control. ${ }^{\# \#} \mathrm{P}<0.01$ compared with control. p-p38, phosphorylated p38 mitogen-activated protein kinase; VEGF, vascular endothelial growth factor.

ginkgolide B promotes proliferation through the Akt/eNOS and MAPK/p38 signaling pathways in bone marrow-derived endothelial progenitor cells (18). Ghosh et al (11) reported that ginkgolide B protects against diethylnitrosamine-induced oxidative damage and may aid in hepatocellular carcinoma prevention through cyclooxygenase-2 and VEGF expression regulation.

In summary, the present study suggested that ginkgolide B treatment increased cell growth, and inhibited apoptosis and caspase-3 activity in EPCs. These results provided novel mechanisms for the molecular function of ginkgolide B and suggested that ginkgolide B may serve as a potential strategy for the amplification of EPCs through the Akt/eNOS/p38/VEGF signaling pathways.

\section{Acknowledgements}

The present study was supported by Jilin Province Department of Education ' 125 ' scientific and technological research projects (grant no. 440030031213 ). 


\section{References}

1. Ng CT, Yip WK, Mohtarrudin N and Seow HF: Comparison of invasion by human microvascular endothelial cell lines in response to vascular endothelial growth factor (VEGF) and basic fibroblast growth factor (bFGF) in a threedimensional (3D) cell culture system. Malays J Pathol 37: 219-225, 2015.

2. Asahara T, Bauters C, Pastore C, Kearney M, Rossow S, Bunting S, Ferrara N, Symes JF and Isner JM: Local delivery of vascular endothelial growth factor accelerates reendothelialization and attenuates intimal hyperplasia in balloon-injured rat carotid artery. Circulation 91: 2793-2801, 1995.

3. Huang Y, Tan Q, Chen R, Cao B and Li W: Sevoflurane prevents lipopolysaccharide-induced barrier dysfunction in human lung microvascular endothelial cells: Rho-mediated alterations of VE-cadherin. Biochem Biophys Res Commun 468: 119-124, 2015.

4. Santulli G: microRNAs Distinctively Regulate Vascular Smooth Muscle and Endothelial Cells: Functional Implications in Angiogenesis, Atherosclerosis, and In-Stent Restenosis. Adv Exp Med Biol 887: 53-77, 2015.

5. Bianchessi V, Badi I, Bertolotti M, Nigro P, D'Alessandra Y, Capogrossi MC, Zanobini M, Pompilio G, Raucci A and Lauri A: The mitochondrial lncRNA ASncmtRNA-2 is induced in aging and replicative senescence in Endothelial Cells. J Mol Cell Cardiol 81: 62-70, 2015.

6. Musiyenko A, Bitko V and Barik S: Ectopic expression of miR-126*, an intronic product of the vascular endothelial EGF-like 7 gene, regulates prostein translation and invasiveness of prostate cancer LNCaP cells. J Mol Med (Berl) 86: 313-322, 2008.

7. Liu X, Sun W, Zhao Y, Chen B, Wu W, Bao L and Qi R: Ginkgolide B Inhibits JAM-A, Cx43, and VE-cadherin expression and reduces monocyte transmigration in Oxidized LDL-stimulated human umbilical vein endothelial cells. Oxid Med Cell Longev 2015: 907926, 2015.

8. Qi XY, Zhang ZX and Xu YQ: Effects of Ginkgolide B on action potential and calcium, potassium current in guinea pig ventricular myocytes. Acta Pharmacol Sin 25: 203-207, 2004.

9. Wang DL, Peng DY, Tao XH, Cao Y, Chen WD, Liang Y, Xie L and Liu XD: The pharmacokinetics and conversion of the lactone to the carboxylate forms of ginkgolide B in rat plasma. J Asian Nat Prod Res 15: 337-343, 2013.

10. Wu X, Zhou C, Du F, Lu Y, Peng B, Chen L and Zhu L: Ginkgolide $\mathrm{B}$ preconditioning on astrocytes promotes neuronal survival in ischemic injury via up-regulating erythropoietin secretion. Neurochem Int 62: 157-164, 2013.

11. Ghosh S, Dungdung SR, Choudhury ST, Chakraborty S and Das N: Mitochondria protection with ginkgolide B-loaded polymeric nanocapsules prevents diethylnitrosamine-induced hepatocarcinoma in rats. Nanomedicine (Lond) 9: 441-456, 2014

12. Livak KJ and Schmittgen TD: Analysis of relative gene expression data using real-time quantitative PCR and the 2(-Delta Delta C(T)) Method. Methods 25: 402-408, 2001

13. Teraa M, Sprengers RW, Schutgens RE, Slaper-Cortenbach IC, van der Graaf Y, Algra A, van der Tweel I, Doevendans PA, Mali WP, Moll FL and Verhaar MC: Effect of repetitive intra-arterial infusion of bone marrow mononuclear cells in patients with no-option limb ischemia: The randomized, double-blind, placebo-controlled Rejuvenating Endothelial Progenitor Cells via Transcutaneous Intra-arterial Supplementation (JUVENTAS) trial. Circulation 131: 851-860, 2015.
14. Rodrigues CG, Plentz RD, Dipp T, Salles FB, Giusti II, Sant'Anna RT, Eibel B, Nesralla IA, Markoski M, Beyer NN and Kalil RA: VEGF 165 gene therapy for patients with refractory angina: Mobilization of endothelial progenitor cells. Arq Bras Cardiol 101: 149-153, 2013 (In English, Portuguese).

15. Tousoulis D, Andreou I, Tsiatas M, Miliou A, Tentolouris C, Siasos G, Papageorgiou N, Papadimitriou CA, Dimopoulos MA and Stefanadis C: Effects of rosuvastatin and allopurinol on circulating endothelial progenitor cells in patients with congestive heart failure: The impact of inflammatory process and oxidative stress. Atherosclerosis 214: 151-157, 2011.

16. Fukao K, Shimada K, Hiki M, Kiyanagi T, Hirose K, Kume A, Ohsaka H, Matsumori R, Kurata T, Miyazaki T and Daida H: Effects of calcium channel blockers on glucose tolerance, inflammatory state, and circulating progenitor cells in non-diabetic patients with essential hypertension: A comparative study between azelnidipine and amlodipine on glucose tolerance and endothelial function-a crossover trial (AGENT). Cardiovasc Diabetol 10: 79, 2011.

17. Riegersperger M, Plischke M, Steiner S, Seidinger D, Sengoelge G, Winkelmayer WC and Sunder-Plassmann G: Effect of conversion from ciclosporin to tacrolimus on endothelial progenitor cells in stable long-term kidney transplant recipients. Transplantation 95: 1338-1345, 2013.

18. Tang Y, Huang B, Sun L, Peng X, Chen X and Zou X: Ginkgolide $\mathrm{B}$ promotes proliferation and functional activities of bone marrow-derived endothelial progenitor cells: Involvement of Akt/eNOS and MAPK/p38 signaling pathways. Eur Cell Mater 21: 459-469, 2011.

19. Santulli G: microRNAs and Endothelial (Dys) Function. J Cell Physiol 231: 1638-1644, 2016.

20. Natarelli L and Schober A: Janus-faced role of Krüppel-like factor 2-dependent regulation of microRNAs in endothelial proliferation. Arterioscler Thromb Vasc Biol 34: 1605-1606, 2014.

21. Hong F, Li Y and Xu Y: Decreased placental miR-126 expression and vascular endothelial growth factor levels in patients with pre-eclampsia. J Int Med Res 42: 1243-1251, 2014.

22. Chen L, Wang J, Wang B, Yang J, Gong Z, Zhao X, Zhang C and Du K: MiR-126 inhibits vascular endothelial cell apoptosis through targeting PI3K/Akt signaling. Ann Hematol 95: 365-374, 2016.

23. Ahsan A, Han G, Pan J, Liu S, Padhiar AA, Chu P, Sun Z, Zhang Z, Sun B, Wu J, et al: Phosphocreatine protects endothelial cells from oxidized low-density lipoprotein-induced apoptosis by modulating the PI3K/Akt/eNOS pathway. Apoptosis 20: 1563-1576, 2015.

24. Meng S, Cao JT, Zhang B, Zhou Q, Shen CX and Wang CQ: Downregulation of microRNA-126 in endothelial progenitor cells from diabetes patients, impairs their functional properties, via target gene Spred-1. J Mol Cell Cardiol 53: 64-72, 2012.

25. Zhu X, Li H, Long L, Hui L, Chen H, Wang X, Shen H and $\mathrm{Xu}$ W: miR-126 enhances the sensitivity of non-small cell lung cancer cells to anticancer agents by targeting vascular endothelial growth factor A. Acta Biochim Biophys Sin (Shanghai) 44: 519-526, 2012. 